\title{
Three-Dimensional Hand-to-Gland Combat: The Future of Endoscopic Surgery?
}

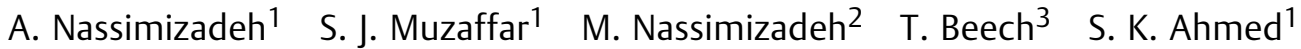 \\ 1 Department of Otorhinolaryngology, Queen Elizabeth Hospital, \\ Birmingham, United Kingdom \\ 2 Department of Plastic Surgery, Queen Elizabeth Hospital, \\ Birmingham, United Kingdom

\begin{abstract}
Address for correspondence Abdul Nassimizadeh, MBChB, BMedSci, Department of Otorhinolaryngology, Queen Elizabeth Hospital, Birmingham, B15 2WB, United Kingdom (e-mail: anassimizadeh@gmail.com).
\end{abstract}

${ }^{3}$ Department of ENT, Birmingham Children's Hospital, Birmingham, United Kingdom

J Neurol Surg Rep 2015;76:e200-e204.

Abstract
Keywords
- surgery
- pituitary
- three-dimensional
- transsphenoidal
- endoscope

Objective To compare two dimensional (2D), three-dimensional (3D) non-highdefinition (HD), and 3D HD endoscopic surgical techniques.

Methods We describe our initial operative experience with a novel 3D HD endoscopic endonasal approach involving a pituitary adenoma resection, provide a case series, and review the current literature. This is the first case in Europe using the new 3D HD endoscope.

Results Although research evidence remains limited, there are no significant negative perioperative or postoperative outcomes when compared with 2D endoscopic techniques. In our experience the narrow operating corridors of endoscopic surgery cannot be addressed with 3D endoscopic techniques. The new 3D HD endoscope creates imaging quality similar to conventional 2D HD systems.

Conclusion Three-dimensional endoscopic endonasal techniques provide an exciting new avenue, effectively addressing potential depth perception difficulties with current 2D systems.

\section{Introduction}

Endoscopic pituitary and skull base surgery was first described in the late 19th and early 20th centuries. ${ }^{1-3}$ However, it was not until 1945 that Karl Storz began producing instruments for otorhinolaryngologists. Although modest, the instruments used miniature electric lamps to visualize the interior of the human body through an endoscope. Despite the complexity of design and $>400$ operations, the visual quality achieved through Storz's work alone would not allow the modern accurate delineation of anatomical structures. Harold Hopkins pursued the limitations of visual quality initially through fiberoptics, but fiber breaks and image resolution limitations forced bundles to be replaced at rapid rates. This in conjunction with poor light transmittance resulted in the final solution from Hopkins in the late 1960s: the Hopkins rod. Hopkins utilized rods of glass in air spaces between the lenses. Due to the size, the rod-lenses would self-align, requiring no further support. Storz subsequently used Hopkins's design, with further modifications to produce what is now considered the modern endoscope.

The last decade has seen dramatic advances in surgical techniques, neuronavigation, and optics including the endoscopic camera and screens. ${ }^{4}$ Despite the endoscope, historically intracranial tumors have been managed by neurosurgeons with various surgical approaches including postauricular, transpetrous, presigmoid, and frontotemporal craniotomy. ${ }^{5-8}$ Endoscopic approaches have the potential to provide more direct access to the tumor site, a reduction in retraction injury to the surrounding normal brain, and a minimization of damage to neurovascular structures. Aesthetically, endoscopic approaches also provide a lack of external scars, as well as decreased patient morbidity and a potentially shorter postoperative recovery period. ${ }^{9-12}$ In addition, vascularized nasal mucosal flaps for dural reconstruction have allowed successful primary and secondary received

October 19, 2014

accepted

December 15, 2014

published online

August 4, 2015
DOI http://dx.doi.org/ 10.1055/s-0035-1547368. ISSN 2193-6358. (c) 2015 Georg Thieme Verlag KG
Stuttgart · New York

License terms

$\Theta(1) \Theta \Theta$ 
repair of skull base defects, helping to further decrease the incidence of postprocedure cerebrospinal fluid (CSF) leaks and further solidify the benefits of an endoscopic endonasal approach. $^{12}$

Most current endoscopic endonasal techniques involve the surgeon working within a two-dimensional (2D) environment. With vision of vital importance in surgery, the 2D nature of surgery creates drawbacks, specifically with regard to a lack of stereopsis impairing depth perception. ${ }^{13}$ This may limit the surgeon's ability to recognize and manage anatomical structures. With the safety of transsphenoidal procedures largely dependent on precise anatomical knowledge, this remains a key concern. ${ }^{14}$ Experienced surgeons compensate for this difficulty through the use of visual and tactile feedback, dynamic movements of the scope, light and shadows, and detailed anatomical knowledge. ${ }^{13}$ However, despite significant experience, these compensatory mechanisms may be misleading, with this effect well described in laparoscopic surgery with visual perceptual illusion the primary cause of error. $^{15,16}$

To mitigate this lack of stereopsis, in 2012 a new threedimensional (3D) endoscope was introduced, designed to overcome these visual difficulties. The first 3D endoscope utilized non-HD technology, producing a balance between stereopsis and visual clarity. As a result, in 2013, high definition (HD) was added to the 3D endoscope. Three-dimensional systems have already been shown to register, validate, and accurately navigate anatomical structures including soft tissue. There is an understandable groundswell of interest for the potential of such systems. ${ }^{14,17}$ We present a case series of endoscopic sinonasal and skull base procedures performed using 3D non-HD scope technology (Visionsense Ltd, Petach Tilka, Israel), as well as the first reported case in Europe using the 3D HD endoscope, comparing these new methods with conventional 2D HD endoscopy.

\section{Three-Dimensional High-Definition Case Report}

A 71-year-old woman presented with a long-standing history of excessive sweating, increase in foot size, and arthralgia. However, there were no significant headaches upon presentation. On examination features of acromegaly were quite subtle. Despite minimal physical alterations, there were a significant number of complications of acromegaly in her medical history including colonic polyp, carpal tunnel syndrome, osteoarthritis, and hypertension.

Biochemical tests confirmed the diagnosis of acromegaly; growth hormone values during a glucose tolerance test were $5.1 \mu \mathrm{g} / \mathrm{L}$. Insulinlike growth factor- 1 was elevated at $84 \mathrm{ng} / \mathrm{L}$. A short Synacthen test with peak cortisol was $861 \mathrm{nmol} / \mathrm{L}$; prolactin was normal. Magnetic resonance imaging of the skull base revealed an $11 \times 8 \times 10 \mathrm{~mm}$ eccentrically placed hypovascular lesion on the right side of the pituitary that was clearly demarcated. There was no compression of the optic chiasm, and the tumor was not invading the cavernous sinus. Subsequent 3D HD endoscopic transsphenoidal surgery under image guidance was performed.

\section{Surgical Technique}

The surgical technique adopted was similar to that used for other transsphenoidal pituitary surgery. The patient was positioned supine. Cocaine and adrenaline were applied topically within the nasal cavity. Following a posterior septectomy, a wide sphenoidotomy was performed preserving the blood supply for a potential rescue nasoseptal flap. Threedimensional HD endoscopic equipment (Visionsense) with intraoperative image guidance (Stryker Nav 3, Fremont, California, United States) was utilized throughout, the former giving increased depth perception not seen with the 2D scope. The bony front wall of the sella turcica was removed exposing the "four blues" (left and right cavernous sinuses, superior and inferior intercavernous sinuses). A clinically apparent adenoma was located to the right of the pituitary, adjacent to the carotid. It was removed with an extracapsular technique. Floseal (Baxter, Hayward, California, United States) was applied for hemostasis followed by Surgicel (Ethicon) and two NasoPore (Stryker) dissolvable nasal packs.

\section{Case Series Using 3D Non-HD Endoscope}

We used the 3D scope on four sequential patients at University Hospitals Birmingham NHS Trust ( - Table 1 ). The surgical technique adopted was similar to that used for conventional 2D endoscopic surgery but with the 3D giving increased depth perception not seen with the $2 \mathrm{D}$ scope.

\section{Surgical Setup for 3D Endoscopy}

The operating room setup for the use of the 3D endoscope and screen, whether HD or not, is slightly different than conventional 2D. The screen is placed further away, to provide an improvement in visual quality, and all members of the surgical staff must wear 3D glasses to visualize the screen appropriately. Rigid head fixation is needed. In our experience, these small changes provided no hindrance to the operating surgeon, and there was no requirement to convert to conventional 2D endoscopy throughout the procedure.

\section{Discussion}

Endoscopic endonasal approaches to the anterior skull base have grown in importance over recent decades, with the skull base having traditionally been solely a neurosurgical preserve. With endoscopic endonasal approaches gaining popularity due to reduced morbidity and superior aesthetic results, anterior cranial fossa malignancies can be safely managed surgically. This is well illustrated by lower levels of CSF leaks, shorter postoperative hospital stays, and a reduced risk of damage to neurovascular structures. ${ }^{5-8}$

Previous well-documented disadvantages of endoscopic surgery, specifically in visual quality, maneuvrability, and narrow visual corridors, have remained a barrier, however. ${ }^{3,14,17}$ Visual quality is of paramount importance because safe surgical techniques require a competent surgeon to judge depth appropriately and recognize important anatomical structures. Traditional 
Table 1 Case series of patients who had three-dimensional non-high-definition endoscopy

\begin{tabular}{|l|l|l|l|l|}
\hline $\begin{array}{l}\text { Patient } \\
\text { demographic }\end{array}$ & Procedure & Indication & $\begin{array}{l}\text { Intraoperative and } \\
\text { postoperative } \\
\text { complications }\end{array}$ & $\begin{array}{l}\text { Need to switch to } \\
\text { conventional two- } \\
\text { dimensional endoscopy? }\end{array}$ \\
\hline $\begin{array}{l}\text { 46-year-old } \\
\text { woman }\end{array}$ & $\begin{array}{l}\text { Transsphenoidal } \\
\text { hypophysectomy }\end{array}$ & $\begin{array}{l}\text { Pituitary-dependent Cushing } \\
\text { syndrome; corticotropinoma }\end{array}$ & Nil & No \\
\hline $\begin{array}{l}\text { 44-year-old } \\
\text { woman }\end{array}$ & $\begin{array}{l}\text { Middle antrostomy } \\
\text { and left-sided biop- } \\
\text { sy of lesion of max- } \\
\text { illary antrum }\end{array}$ & $\begin{array}{l}\text { Two decades of left-sided facial } \\
\text { pain }\end{array}$ & Nil & No \\
\hline $\begin{array}{l}\text { 78-year-old } \\
\text { woman }\end{array}$ & $\begin{array}{l}\text { Endoscopic drain- } \\
\text { age of right maxil- } \\
\text { lary mucocele, } \\
\text { expanding into } \\
\text { right nasal cavity }\end{array}$ & $\begin{array}{l}\text { Right-sided epiphora and nasal } \\
\text { obstruction, with a back- } \\
\text { ground of nasal bridge injury }\end{array}$ & Nil & No \\
\hline $\begin{array}{l}\text { 38-year-old } \\
\text { woman }\end{array}$ & $\begin{array}{l}\text { "Re-do" transsphe- } \\
\text { noidal } \\
\text { hypophysectomy }\end{array}$ & $\begin{array}{l}\text { Pituitary-dependent } \\
\text { acromegaly }\end{array}$ & Nil & No \\
\hline
\end{tabular}

endoscopic techniques function within a $2 \mathrm{D}$ environment, resulting in potential drawbacks in depth perception.

An experienced surgeon develops compensatory mechanisms, relying on tactile feedback, scope movements, and anatomical knowledge. However, in the presence of distorted anatomy, difficulties with depth perception are heightened. Visual perceptual illusions can be a major cause of error and resultant morbidity. ${ }^{18}$ Recently, 3D endoscopic techniques opportunities have become a commercial and clinical reality, with the aim of mitigating the drawbacks of the $2 \mathrm{D}$ endoscopic. Despite these technological advances, research evidence remains limited, although subjective reports from both otorhinolaryngologists and neurosurgeons suggest that 3D technology improves task speed and efficiency. ${ }^{10,11}$

\section{Three-Dimensional Non-HD Endoscopy}

Despite improvements in depth perception, some limitations of endoscopic endonasal surgery remain including decreased maneuverability within narrow spaces. The reduced field of view obtained with new 3D endoscopes results in narrow corridors appearing even narrower, due to the 3D optic lens being less divergent and providing a slightly narrower view. These issues cannot be addressed with 3D endoscopic techniques and remain solely the responsibility of the operating surgeon, specifically by experience and optimum scope placement. Within our experience this did not cause any surgical problems. The non-HD 3D endoscope also has slightly worse blood soiling, due to the presence of two chips and two lenses, each representing a single eye. As a result, blood soiling to a single lens will cause unilateral visual difficulties. Screen irrigation systems maintained from conventional 2D endoscopes reduce the significance of this blood soiling. The largest drawback of the non-HD 3D endoscope relate to image quality with HD 2D imaging more defined and displaying better contrast, although this has not been found to alter surgical technique or outcomes significantly. ${ }^{13,19}$

\section{Three-Dimensional HD Endoscopy}

Although reduced lens divergence and resultant narrow corridors continue to be present in the new HD endoscope, each single lens is composed of numerous planes, similar to the eye of a fly. This improvement of the lens leads to better results in relation to blood soiling and subsequent image clarity. As mentioned previously, the greatest drawback of the non-HD 3D endoscope was image quality and contrast. Threedimensional HD endoscopy overcomes this drawback with image quality similar to that of conventional HD 2D imaging. The system also has an inherent focus system, which allows image quality to remain consistent throughout the working depths of endoscopic surgery, with the option of manual focusing if required. In our experience manual focusing is only needed rarely. When comparing 2D HD with 3D non-HD and 3D HD endoscope systems (-Table 2), we found maneuvrability similar in all systems, but visual corridors remained superior in the conventional 2D HD system. Blood soiling of the endoscope tip and image quality was most problematic in the 3D non-HD system, and all three systems were simple to use and easy to set up.

Although research involving 3D endoscopy remains limited, small studies have highlighted no significant negative perioperative or postoperative outcomes when compared with 2D endoscopic techniques in novel users with regard to operative times, blood loss, CSF leaks, length of stay, or readmission rates. ${ }^{17,20}$ However, there is a need for rigid head fixation. With acclimatization to the equipment it has been shown to be time effective, cost efficient, safe, and technically beneficial. ${ }^{15,21}$ These advantages, coupled with the scope for improvement and new evolution of 3D image technology, provides an exciting prospect for the future of anterior skull base surgery. The evolution in endoscopy is comparable with the conception and advancement of modern-day television; from low pixelated black-and-white images, to color, followed by increased resolution before the introduction of HD televisions and the current 
Table 2 Comparison of endoscopic systems ${ }^{\text {a }}$

\begin{tabular}{|l|l|l|l|}
\hline & 2D HD system & 3D non-HD system & 3D HD system \\
\hline Maneuvrability & +++ & +++ & +++ \\
\hline Visual corridors & +++ & ++ & ++ \\
\hline Blood soiling & +++ & ++ & +++ \\
\hline Depth perception & + & +++ & +++ \\
\hline Image quality & +++ & ++ & +++ \\
\hline Ease of surgical Setup & +++ & +++ & +++ \\
\hline
\end{tabular}

Abbreviations: 2D, two dimensional; 3D, three dimensional; HD, high definition.

'Based on the authors' experience.

$+++=$ Good.

$++=$ Room for improvement.

$+=$ Poor.

surge of 3D functional systems. As a result, we believe 3D endoscopy not to be a revolution, but instead the next logical evolution in endoscopic surgery. The biggest advantage is for neurosurgeons who currently use the microscope for stereoscopic surgery because there is retention of stereopsis, resulting in a far easier transition than to conventional 2D endoscopy. Otorhinolaryngologic surgeons, in contrast, have used 2D images throughout their training, so the advantages in additional information are far less apparent.

\section{Conclusion}

Three-dimensional endoscopic endonasal techniques provide an exciting new avenue for anterior skull base surgery, effectively addressing potential depth perception difficulties with current $2 \mathrm{D}$ systems. The new 3D HD system negates the main drawback from previous 3D endoscopes; image quality, with resolution and contrast, are comparable with conventional 2D endoscopy.

Notes

Full informed consent was obtained from all patients prior to data collection. All patient data was anonymized before to data analysis.

\section{References}

1 Pollock JR, Akinwunmi J, Scaravilli F, Powell MP. Transcranial surgery for pituitary tumors performed by Sir Victor Horsley. Neurosurgery 2003;52(4):914-925; discussion 925-926

2 Caton R. Notes of a case of acromegaly treated by operation. BMJ 1893;2(1722):1421-1423

3 Schloffer H. On the problem of surgery on the pituitary gland. Beitr Klin Chir 1906;50:767-817

4 Lee SC, Senior BA. Endoscopic skull base surgery. Clin Exp Otorhinolaryngol 2008;1(2):53-62

5 Behari S, Tyagi I, Banerji D, et al. Postauricular, transpetrous, presigmoid approach for extensive skull base tumors in the petroclival region: the successes and the travails. Acta Neurochir (Wien) 2010;152(10):1633-1645

6 Kusumi M, Fukushima T, Mehta AI, et al. Tentorial detachment technique in the combined petrosal approach for petroclival meningiomas. J Neurosurg 2012;116(3):566-573
7 Shi W, Shi JL, Xu QW, Che XM, Ju SQ Chen J. Temporal base intradural transpetrosal approach to the petoclival region: an appraisal of anatomy, operative technique and clinical experience. Br J Neurosurg 2011;25(6):714-722

8 Mathiesen T, Gerlich A, Kihlström L, Svensson M, Bagger-Sjöbäck D. Effects of using combined transpetrosal surgical approaches to treat petroclival meningiomas. Neurosurgery 2008;62; (6, Suppl 3):1213-1223

9 Sekhar LN, Tariq F, Ferreira M. What is the best approach to resect an anterior midline skull base meningioma in 2011? Microsurgical transcranial, endonasal endoscopic, or minimal access cranial? World Neurosurg 2012;77(5-6):621-622

10 Gardner PA, Kassam AB, Thomas A, et al. Endoscopic endonasal resection of anterior cranial base meningiomas. Neurosurgery 2008;63(1):36-52; discussion 52-54

11 Oostra A, van Furth W, Georgalas C. Extended endoscopic endonasal skull base surgery: from the sella to the anterior and posterior cranial fossa. ANZ J Surg 2012;82(3):122-130

12 Snyderman CH, Pant H, Carrau RL, Prevedello D, Gardner P, Kassam $\mathrm{AB}$. What are the limits of endoscopic sinus surgery?: the expanded endonasal approach to the skull base Keio J Med 2009;58(3): $152-160$

13 Castelnuovo P, Battaglia P, Bignami M, et al. Endoscopic transnasal resection of anterior skull base malignancy with a novel 3D endoscope and neuronavigation. Acta Otorhinolaryngol Ital 2012;32(3):189-191

14 Eboli P, Shafa B, Mayberg M. Intraoperative computed tomography registration and electromagnetic neuronavigation for transsphenoidal pituitary surgery: accuracy and time effectiveness. J Neurosurg 2011;114(2):329-335

15 Fraser JF, Allen B, Anand VK, Schwartz TH. Three-dimensional neurostereoendoscopy: subjective and objective comparison to 2D. Minim Invasive Neurosurg 2009;52(1):25-31

16 Way LW, Stewart L, Gantert W, et al. Causes and prevention of bile duct injuries: analysis of 252 cases from a human factors and cognitive psychology perspective. Ann Surg 2003;237(4): 460-469

17 Waran V, Menon R, Pancharatnam D, et al. The creation and verification of cranial models using three-dimensional rapid prototyping technology in field of transnasal sphenoid endoscopy. Am J Rhinol Allergy 2012;26(5):e132-e136

18 Roth J, Singh A, Nyquist G, et al. Three-dimensional and 2-dimensional endoscopic exposure of midline cranial base targets using expanded endonasal and transcranial approaches. Neurosurgery 2009;65(6):1116-1128; discussion 1128-1130

19 Tabaee A, Anand VK, Fraser JF, Brown SM, Singh A, Schwartz TH. Three-dimensional endoscopic pituitary surgery. Neurosurgery 2009;64(5, Suppl 2):288-293; discussion 294-295 
e204 Three-Dimensional Hand-to-Gland Combat Nassimizadeh et al.

20 Brown SM, Tabaee A, Singh A, Schwartz TH, Anand VK. Three-dimensional endoscopic sinus surgery: feasibility and technical aspects. Otolaryngol Head Neck Surg 2008;138(3): 400-402
21 Kari E, Oyesiku NM, Dadashev V, Wise SK. Comparison of traditional 2-dimensional endoscopic pituitary surgery with new 3-dimensional endoscopic technology: intraoperative and early postoperative factors. Int Forum Allergy Rhinol 2012;2(1):2-8 